Binghamton University

The Open Repository @ Binghamton (The ORB)

$9-1-2014$

\title{
Do Human Resource Departments Act as Strategic Partners? Strategic Human Capital Management Adoption by County Governments
}

Willow S. Jacobson

The University of North Carolina at Chapel Hill

Jessica E. Sowa

University of Colorado Denver

Kristina T. Lambright

Binghamton University--SUNY, klambrig@binghamton.edu

Follow this and additional works at: https://orb.binghamton.edu/public_admin_fac

Part of the Public Administration Commons

\section{Recommended Citation}

Jacobson, Willow S.; Sowa, Jessica E.; and Lambright, Kristina T., "Do Human Resource Departments Act as Strategic Partners? Strategic Human Capital Management Adoption by County Governments" (2014). Public Administration Faculty Scholarship. 49.

https://orb.binghamton.edu/public_admin_fac/49

This Article is brought to you for free and open access by the Public Administration at The Open Repository @ Binghamton (The ORB). It has been accepted for inclusion in Public Administration Faculty Scholarship by an authorized administrator of The Open Repository @ Binghamton (The ORB). For more information, please contact ORB@binghamton.edu. 


\title{
Do Human Resource Departments Act as Strategic Partners? Strategic Human Capital Management Adoption by County Governments
}

\author{
Abstract \\ Drawing on qualitative data from forty counties in New York and North Carolina, this article \\ examines the adoption of strategic human capital management (SHCM) principles and practices \\ at the county level and presents a typology of five levels of SHCM adoption. The level of SHCM \\ implementation in a county depends on: the view of the HR function by executive county \\ leadership, the capacity of the county to engage in strategic planning and management, and the \\ capacity of the HR director to think strategically about the role of HR in the government. The \\ article concludes with recommendations for practice, which focus on educating a diverse set of \\ actors about SHCM, building executive level support, developing HR skill and competencies, \\ and applying basic change management practices.
}




\section{INTRODUCTION}

Since the advent of public administration as a discipline, researchers have tried to identify the best strategies for managing government workforces (Condrey, 2010; Dresang, 2009; Van Riper, 1958; Mosher, 1968; Ingraham, 1995; Riccucci \& Naff, 2008). There is growing empirical evidence that human resource management (HRM) practices have a direct impact on organizational performance (Ulrich, Brockbank, Johnson, Sandholtz, \& Younger, 2008; Lawler \& Boudreau, 2009). While scholars have been arguing for a more strategic approach to the HR function in the public sector for almost twenty years, in practice the recognition and appreciation by practitioners that HRM can impact the strategic direction and overall performance of public organizations has been a more recent shift (Ospina, 1992; Perry, 1993; Daley, 2002; Crumpacker \& Crumpacker, 2004; Selden, 2009; Perry, 2010).

The strategic approach to HRM, referred to as strategic human capital management $(\mathrm{SHCM}),{ }^{\mathrm{i}}$ is based on the idea that "people, or the human capital of an organization, can play a strategic role in the organization's success" (Selden, 2009, p. 15). Studies of public employment

at the federal, state, and local levels in the United States consistently advocate for the adoption of this approach and have documented particular patterns of change in relation to strategic HRM in practice (Crumpacker \& Crumpacker, 2004; Selden 2009). Still, more research is required to understand the process of changing HRM culture in public organizations to this more strategic approach.

Drawing on qualitative data from forty counties in New York and North Carolina, the extent to which local government HR professionals are playing a strategic leadership role in the overall management of counties and implementing practices associated with SHCM is examined. This research adds to knowledge about HRM managers' leadership in SHCM implementation, 
revealing that the adoption of SHCM is an on-going process for county governments. The level of SHCM in a county depends on: the view of the HR function by executive county leadership, the capacity of the county government to engage in strategic planning and management, and the capacity of the HR director to think strategically about the role of HR in the government.

Based on the results, a deeper understanding of county HR practices is gained, a level of government where there has been a call for greater research attention (Benton, 2005; Menzel et al, 1992; Rush \& Kellough, 2011; Streib et al, 2007; Svara, 1996). This research presents five models of SHCM implementation across these county governments. While there has been increasing scholarly interest in SHCM, the development of a typology for classifying the different levels of SHCM represents an important contribution to HR research and practice, as this typology provides insights into the SHCM adoption process. This article concludes by discussing implications for practice.

\section{Strategic Human Capital Management}

The SHCM approach to the HR function is a departure from previous methods of managing people in government. The traditional civil service system emphasizes routine and structure, creating a system of classified jobs where separation between positions is clear and positions are arranged in a strict hierarchy of authority (Van Riper, 1958; Mosher, 1968; Ingraham, 1995; Kellough, Nigro, \& Brewer, 2010; Condrey, 2010). Although the traditional approach to managing people in government has some benefits, the emphasis on administration of HR policies and regulation of the personnel function inhibits this system from fully viewing public employees as valuable assets. Over the last two decades, there has been a call for a transition from traditional personnel administration to SHCM, recognizing that HR should be a strategic partner with management to achieve strategic and organizational goals (Perry 1993; 
Daley, 2006; Pynes, 2009; Selden, 2009; Perry, 2010). Many HR departments have shifted from a role focused primarily on administrative functions (such as payroll, compliance and record keeping), to a more operational role, and finally to a largely strategic role (Selden \& Jacobson, 2003, 2007; Nigro, Nigro, \& Kellough, 2007; Daley, 2006; Selden, 2009, Perry, 2010).

There may be variations depending on the government unit, but adopting SHCM generally requires that agencies develop an overall strategic plan as well as a human capital plan that integrates the workforce requirements with the goals identified in the strategic plan. According to Tompkins (2002), the alignment of personnel policies and practices with an organization's strategic objectives is the core requirement of SHCM. The general operational steps of this approach include: 1) identifying the strategic direction of the government unit, 2) analyzing workforce requirements to achieve this strategic direction, ${ }^{\mathrm{ii}}$ and 3) developing action plans for the HR function that will help achieve the overall strategic goals of the department.

SHCM requires a different way of thinking about the functional requirements of the HR department. As departments or agencies take on more strategic roles, they may need to relinquish other responsibilities and/or determine ways to balance traditional administrative functions with their new strategic role. HR departments will still be involved with administrative functions such as payroll and record keeping, responding to problems and requests, and developing new programs. However, they may need to rethink how they manage these responsibilities when taking on new leadership roles in the government as a whole, including using strategies such as decentralization or contracting with other internal and external entities to fulfill core functions. Under this model, the HR department focuses on examining what HRM brings to the government as a whole separate from the administrative functions of the department, adopting a more transformational role in addition to the traditional transactional role of HRM. ${ }^{\text {iii }}$ 
Little is known about the extent to which SHCM has been implemented by local governments. Drawing on results from the evaluation of municipal, county and state government HR systems, Selden and Jacobson (2003) found that SHCM adoption in city and county governments have been slower than in states. This article continues this examination by exploring how HR functions at the county government level. Specifically it focuses on the role of county HR managers in strategic planning and the degree to which these HR departments are strategic leaders. While this study is exploratory, results indicate that many HR departments have implemented some SHCM principles but full adoption of SHCM is still not common.

\section{MethodologY}

To learn about the HR professionals' strategic leadership in county government, county HR directors were interviewed in North Carolina and New York. These states were selected because they differ in terms of political culture, civil service laws, and union activity. Forty semi-structured interviews with randomly selected county HR directors were conducted from August 2010 to December 2010: 20 interviews in New York and 20 interviews in North Carolina. Counties within the greater New York City area were excluded from the sampling frame. The sampling frame was also limited to counties with a workforce greater than 500 employees to ensure that the workforce size would be sufficient to warrant a county-level HR director position with relevant HR functional responsibilities.

While the unit of data collection was the HR director, the unit of analysis was the HR department. The data used for this study was part of a larger research project. This study focuses on HR directors' answers to questions about their department's role in the strategic planning process in their county and the extent to which their county manager viewed HR as a strategic function, a support function or some combination of both. To minimize concerns about social 
desirability bias, these questions were asked at the end of the protocol with other background information questions about the respondents and their respective counties. The questionnaire was pre-tested with HR directors from two city governments. Key characteristics of the sample include:

- approximately three-quarters of respondents had 11 or more years of HR experience but slightly less than half had been HR director for more than 5 years;

- $45 \%$ of respondents had private sector work experience;

- $25 \%$ of respondents worked in counties with populations with less than 75,000 residents, $55 \%$ worked in counties with populations between 75,000 and 225,000, and 20\% worked in counties with populations greater than 225,000 ;

- $32.5 \%$ of respondents worked in counties with between 500 and 749 employees, $47.5 \%$ worked in counties with between 750 and 2,249 employees, and the remainder worked in counties with 2,500 or more employees.

All interviews were recorded and transcribed, and data were analyzed using the qualitative data analysis software QSR NVivo (Version 8). ${ }^{\text {iv }}$ The data analysis process included both deductive and inductive approaches and was conducted in several phases. Coding definitions were developed in order to ensure consistent usage. Both pattern-matching (Yin, 1994) and memoing (Miles \& Huberman, 1994) were used as part of the data analysis.

\section{FINDINGS}

Examining patterns across the forty counties, five different models of the HR functional role in county government were identified, based on the following characteristics:

1. There is a strategic plan at the county level. Organizations need to have clear goals in order to connect human resources to the achievement of those goals (Selden, 2009). If a county government lacks a strategic plan, it cannot fully implement SHCM.

2. The HR manager plays a strategic role in county government. To engage in SHCM, the HR director must understand and demonstrate that $\mathrm{HR}$ adds value outside of the support or administrative role they play and that HR planning and management can have a 
significant impact on how county government functions. The HR director must also communicate the importance of the HR function to key stakeholders.

3. County leaders recognize HR is a strategic function. Even an HR director who is a strong advocate for SHCM will be unsuccessful if there is no audience or support for that message. In order for SHCM to be adopted, executive county leadership, including the county manager, must view HR as playing a key role in the strategic planning process. Table One highlights the relationship between these three dimensions and the five models developed in this research.

\begin{tabular}{|llll|}
\hline & $\begin{array}{l}\text { Strategic Plan at } \\
\text { the County } \\
\text { Level? }\end{array}$ & $\begin{array}{l}\text { HR Manager } \\
\text { Plays Strategic } \\
\text { Role? }\end{array}$ & $\begin{array}{l}\text { HR Function } \\
\text { Viewed by Top } \\
\text { Management as } \\
\text { Strategic? }\end{array}$ \\
\hline Model 1 & Yes & No & No \\
\hline Model 2 & Yes & No, but interested & No, but interested \\
\hline Model 3 & No & Yes & Yes \\
\hline Model 4 & Yes & Yes, somewhat & Yes, somewhat \\
\hline Model 5 & Yes & Yes & Yes \\
\hline
\end{tabular}

While the level of SHCM tends to increase across the five models, there is not a linear path between models. Each model represents a unique set of characteristics, and various paths can be followed in adopting SHCM.

\section{Model One: Traditional Personnel Approach}

Three counties had traditional personnel structures. The HR director and executive county leadership demonstrated little recognition that HR could play a role in establishing the county's strategic direction and provided little indication that changes in the function of HR were forthcoming or even possible. Across these three counties, the HR department was viewed purely as a support function. When asked the extent the county manager used HR as a strategic function 
rather than as a support function, one respondent noted "Probably very little, much more significantly at the support level." This quote represents the sentiment expressed across the Model One counties. These HR departments were not included the planning process and solely focused on the traditional administration of personnel policies. In addition, the HR director did not realize the potential value in having their department play a more strategic role. The possibility of changing the role of the HR department in these counties appears unlikely under the current HR and executive county leadership.

\section{Model Two: Traditional Personnel Approach but Hoping for More}

Five county HR departments had traditional personnel structures and were not involved in the strategic planning function. However, unlike Model One counties, the HR director recognized the problems with this approach. These directors believed that their department should be involved in the county's strategic planning and that HRM could contribute more to the overall leadership and performance of the county. They also indicated that there were barriers to their department playing a strategic leadership role.

In all five of the counties, the HR directors reported that key county officials did not fully appreciate how HRM could contribute to the broader strategic development and management of government. For example, one HR director indicated that HR's historical function has prevented executive county leadership from recognizing what HR can contribute to the strategic planning process. This respondent stated:

I think HR has been neglected as its own organization and what it can bring to the larger organization. Because of the history, it was seen as paper pushers. I have been telling my staff that we are the example of what employees should be for the entire county. We are 
what customer service should be for the entire county. We can have a strong leadership role.

This example demonstrates that it is not enough for the HR director to realize the leadership role HR can play; there also must be a change in how executive county leadership views HRM.

\section{Model Three: HRM Partner Approach in a Strategically Deficient Organization}

In another four counties, HR directors were thinking and acting strategically. They worked closely with the executive county leadership on key management decisions, and the executive county leadership viewed the HR department as having a role in setting and supporting strategy. These HR directors either served on the management team or found ways to inform management about HR's strategic role within the organization. Inclusion of the HR director in strategic management decisions took place through both formal and informal channels. For example, one HR director commented:

The County Manager looks at it [HR] as a strategic partner because I think he understands the importance of it's the people that help make you successful. The HR Director is part of the management team... He and I speak on a daily basis as well. This is an organization where I felt a part of the management team.

However, none of the counties categorized in Model Three had a systematic strategic planning process in place at the county level. As a result, these four counties could not be classified as fully adopting SHCM. Still, the HR department in these counties is positioned to be able to move closer to adopting the SHCM model if these counties decide to initiate strategic planning efforts. These departments could participate in future planning efforts as well as actively promote the importance of adopting a county-wide strategic planning process.

\section{Model Four: Expert Consultant Approach}


In twelve counties, the HR department participated in the county's strategic planning process but with clear boundaries on their inclusion. The HR director's role in the strategic planning process is best described as an expert consultant rather than as a full partner. In this model, HR directors may be asked to provide advice concerning the impact of strategic goals on existing positions, to collect data to help justify strategic goals, and/or to talk about the associated HR requirements of particular goals. However, the HR director and the HR department, instead of being a full partner in these discussions, are used more as a resource, similar to the use of a county attorney's office to approve new policies. As one North Carolina director noted:

We're very involved, not at the top. This County Manager brings us in on a lot more than the prior manager. He doesn't have a senior manager group. I'm not in the group that develops the comprehensive plan for the county. There may be something in there that is HR related, and I'm brought in on that. Anything that happens in the county where the manager believes it is an HR issue, he comes to me.

\section{Model Five: Strategic Partner Approach}

Finally, sixteen counties have adopted SHCM. Counties classified in Model Five included counties with small, medium, and large populations, indicating no clear pattern between population size and adoption of SHCM. In Model Five counties, the HR director is a central figure in the strategic planning process, and the input of the HR director is viewed as critical by executive county leadership. As part of the strategic planning process, the HR director is a key participant in conversations about HR needs for accomplishing strategic goals as well as in conversations about topics that are not purely within the purview of the HR department. Although the HR director is integral to their county's strategic planning process, these 
departments were still simultaneously performing the more traditional functions of an HR department. In Model Five compared to the other models, there is a greater balance between the strategic and support roles rather than the department focusing primarily on the support function.

Respondents in this category all maintained that they had a full "seat at the table" for management meetings. Nonetheless, there is considerable variation within this model. One subset comprises counties completely integrated into the strategic planning process while another is made up of counties with HR directors still developing their roles as strategic partners. For example, four of the HR directors commented that having the HR department play a strategic role was new. As one respondent notes: "We're very involved [in the strategic planning process]. We definitely have a seat at the table. That is not something we had three, four years ago." In implementing SHCM, some HR directors recognized the need to advocate for the transition. Quinn, Faerman, Thompson, and McGrath (2003) highlight the importance of the broker role for leaders. In two counties, HR directors have played this role. For example, one of these HR directors commented:

We are always at the table when top-level managers in the county are together. We are always there. The commissioners call on us quite often. Several people have asked how I was able to swing that, and I said you have to let them know how valuable you are. I've attended SHRM [Society for Human Resource Management] conferences and told them things in my role and they want to know how we got to this point. You have to share your knowledge base and it becomes a natural thing for managers.

While in some counties the HR professionals have actively made the case for SHCM, the impetus for change was the county manager in another two counties. 
Two themes emerged in the interviews as reasons why HR directors believed their counties were able to adopt SHCM. Four respondents emphasized the critical impact that HRM has on a county's overall performance and believed this close relationship was the driving force for their inclusion and role with the management team. In the words of one HR director, "From a cost standpoint and operational, it comes down to bodies and we manage those bodies so I'm at the table for every major decision that's made in the County Executive's office." The second reason attributed to facilitating the transition to SHCM was the HR director's development of strong working relationships with key stakeholders underscoring the importance of individual HR professionals' leadership skills and abilities. Reflecting the sentiments of five interviewees, one HR director commented: "We are very much involved in everything. There isn't much that goes on in the county that I'm not involved with first hand."

The extent to which the HR directors are integrated into the strategic process and the impetus for the transition to SHCM varied in the counties classified in Model Five. However, the key commonality across all of these counties is that they are partners with the rest of the management team and play a crucial role in helping their counties to think and act strategically.

\section{IMPLICATIONS FOR PRACTICE}

Looking across these five models, several lessons can be drawn. Managers need to recognize that transitioning to a more SHCM role is a change process and as such it will need to be managed and tailored to the organization and community. There is no one perfect way to implement SHCM - taking care to tailor the implementation to local capacity and circumstances may lead to more successful results. SHCM requires a fundamental rethinking of the role of HR professionals in managing the workforce and, like all changes, involves risks. It is often believed that larger organizations are more likely to adopt SHCM (Lawler, 2005). Yet, the 
results did not indicate an association between model classification and county population size. This highlights organizations regardless of their size have the potential to adopt SHCM if they wish. Some governments may not want to invest in the adoption of SHCM, no matter how well documented the personnel and performance gains. It is important to determine if changing the role of HR is appropriate for the organization. If, like seen in Model One cases, there is no interest from the HR staff or executive staff, then pursuing a transition may not be appropriate despite noted benefits. These communities may want to determine if there are aspects of SHCM that are, or should be, performed through a different mechanism, such as human capital planning based in the executive's office.

Among HR departments in Model Two counties, there was a growing recognition that their role should be more strategic in nature. However, Model Two counties demonstrate that even when HR managers recognize the need for change, a broader set of stakeholders need to be engaged in order for change to occur. To develop the needed support of key stakeholders, education related to the differences and benefits of the SHCM approach is often a critical first step. HRM actions or events such as turnover, new hires, or RIFs can serve as opportunities for HR managers to initiate a dialogue with management about how SHCM could assist the government in achieving new performance gains. Successfully taking advantage of opportunities to introduce SHCM concepts to management will encourage further strategic thinking and action that incorporates HR professionals and perspectives. Success breeds opportunities for further success; use these opportunities to celebrate wins that can strengthen the change process.

Even when the organization is not fully engaged in strategic behavior and lacks a countywide strategic plan, such as was seen in Model Three governments, HR professionals similarly can harness numerous opportunities to have strategic discussions and encourage other officials to 
think strategically and align HR practices to government goals. This in the long run will help the government think and act more strategically. Through building on successful experiences, even when small, the HR staff can help build the capacity of both the HR department and executive staff. HR professionals will want to model strategic thinking and planning, adopting a long-term perspective and using performance based decision making. The more that HR managers can make decisions based on performance data, the more decisions may be seen legitimate and credible by various stakeholders. Performance measurement to help document and track SHCM impact can provide important information for both the HR department day to day and serve as the empirical base to demonstrate the need for changing roles.

Even when HR gains a seat at the management table, this does not necessarily indicate that the SHCM implementation process is complete. HR directors in Model Four were expert consultants rather than full partners in the overall management process. They had greater influence in the strategic planning process compared to directors in Models One, Two, and Three but they were not involved in establishing county-wide strategic goals. While the specific barriers to achieving full SHCM in Model Four counties were not examined, responses from both Model Four and Model Five counties indicate that as HR professionals demonstrate their department's strategic value, they build credibility with key stakeholders increasing their involvement in the broader decision making process. Within Model Four counties, educating key personnel on the benefit of expanding HR's role again is critical as is building the capacity within HR to serve an expanded role. A challenge with implementation is the need to both garner buy-in and support for a changing role of the HR function while at the same time ensuring that HR professionals have the necessary competencies and capacity to serve in the expanded role. Organizations will need to invest in their HR staff to develop the skills and competencies to 
serve in expanded roles successfully. These skills include: 1) collaborating with management, participating in the management team, and sharing accountability for organizational results, 2) ensuring that the HR department upholds public values and advocates for employees, and 3) being a change activist by showing the need for change, facilitating that change, and getting the government as a whole to recognize the need to build strategy and adaptability into the workforce (U.S. Office of Personnel Management, 1999, 2000; Brockbank, Johnson, \& Ulrich, 2008).

When implementing this model and attaining these skills, there is still variation in how different governments approach SHCM. For example, HR directors in Model Five reported that they were all strategic actors within their governments and served as part of the top management team, yet these counties differed in the sophistication of SHCM and the integration of the HR director into the strategic planning process. These differences suggest that SHCM "implementation" is not necessarily something that is ever completed. Continued development, coaching, and training of both the HR staff as well as key public officials will be needed to ensure SHCM's success. This research illustrates that HR leadership is key in SHCM implementation. As reported by HR managers in Model Five, county HR managers have the potential to play a critical role in the change process through education and advocacy. In addition, several HR directors from Model Five counties emphasized the importance of having a working relationship with management and building a sense of confidence and contribution.

In implementing SHCM, leadership is needed not only from the HR director but also from the executive level. Without this top-down acknowledgement of the strategic role HRM, it will be difficult, if not impossible, to initiate true SHCM. In counties where HR directors recognize that their departments can play a more strategic role but executive county leadership 
does not (Model Two), education may be critical. Pointing out the importance and possible contributions of the HR function and the value it can bring to accomplishing the government's goals may convince these leaders to change their county's management culture. Planning is key for managing any changes to professionals and institutional roles and responsibilities. Educating people about how changes will impact them and recognizing the need to continue to evaluate and develop roles across time are critical steps in implementing SHCM. Resistance is a natural part of any change and should be expected. Organizations interested in implementing changes to the role of the HR department will need to determine how to deal with the resistance. Building on small successes that demonstrate the value of having HR in a more strategic role can serve as an important step in overcoming initial skepticism. Ensuring that the shift to SHCM is gradual and systematic and that organizational structure and procedures support the new model and reinforce the role of HR as a strategic partner also increase the likelihood SHCM will be successful.

\footnotetext{
${ }^{\mathrm{i}}$ The terms strategic human capital management and strategic human resource management are often used interchangeably in the HRM research. Selden (2009) explores how SHCM arose from SHRM, with both sets of research integrating the concepts of strategic planning and human capital management into an overall process of managing people to direct them toward the accomplishment of organizational goals. For the sake of clarity, this research uses the phrase strategic human capital management, afterward referred to as SHCM.

${ }^{i i}$ Workforce planning is a significant component of this part of the SHCM process. For more detailed treatments of workforce planning, see Selden (2009) and Pynes (2009).

iii Transactional components of HRM include the traditional administrative components discussed (e.g. payroll, employment paperwork). Transformational components of HRM include HR managers operating as change agents and leaders to shape how employees experience the workplace and connecting these human resources to the accomplishment of organizational goals (U.S. Office of Personnel Management, 1999, 2000; Brockbank, Johnson, \& Ulrich, 2008).

iv We used QSR Nvivo 8 to help us organize the qualitative data collected for this study and to identify common themes in the interviews.
} 


\section{REFERENCES}

Benton, J. E. (2005). An assessment of research on American counties. Public Administration Review, 65, 462-474.

Brockbank,W., Johnson, D., and Ulrich, D. (2008). Mastery at the intersection of people and business. Alexandria, VA: Society for Human Resource Management.

Condrey, S. E., ed. (2010). Handbook of Human Resource Management in Government, 3rd edition. San Francisco, CA: Jossey-Bass Publishers.

Crumpacker, M. and Crumpacker, J.M. (2004). Elevating, integrating, and institutionalizing strategic human capital management in federal agencies through the chief human capital officer. Review of Public Personnel Administration, 24, 234-255.

Daley, D.M. (2002). Strategic human resource management: People and performance management in the public sector. Upper Saddle River, NJ: Prentice Hall.

Dresang, D. L. (2009). Personnel management in government agencies and nonprofit organizations. New York: Pearson Longman.

Ingraham, P. W. (1995). The foundation of merit: Public service in American democracy. Baltimore, MD: Johns Hopkins University Press.

Kellough, J. E., Nigro, L. G. and Brewer, G. A. (2010). Civil service reform under George W. Bush: Ideology, politics and public personnel administration. Review of Public Personnel Administration, 30, 404-422.

Lawler III, Edward E and Boudreau, John W. (2009). Achieving excellence in human resources management: An assessment of human resource functions. Stanford, CA: Stanford University Press.

Menzel, D. C., Marando, V. L., Parks, R. B., Waugh, W. L.,Jr., Cigler, B. A., Svara, J. H., et al.. (1992). Setting a research agenda for the study of the American county. Public Administration Review, 52,173-182.

Miles, M. B. and A. M. Huberman (1994).Qualitative data analysis: An expanded sourcebook ( $2^{\text {nd }}$ ed.). Thousand Oaks, CA: Sage Publications.

Mosher, F.C. (1968). Democracy and the public service. Oxford University Press.

Nigro, L., Nigro, F., and Kellough, J.E. (2007). The new public personnel administration $\left(6^{\text {th }}\right.$ ed.). New York: Wadsworth.

Ospina, S. (1992). When managers don't plan: Consequences of nonstrategic personnel management. Review of Public Personnel Administration, 12, 52-67. 
Perry, J. L. (1993). Strategic human resource management. Review of Public Personnel Administration, 13, 59-71.

Perry, J. L. (2010). A Strategic agenda for public human resource management research. Review of Public Personnel Administration, 30, 20-43.

Pynes J.E. (2009). Human resources management for public and nonprofit organizations ( $3^{\text {rd }}$ ed.). San Francisco, CA: Jossey-Bass.

Quinn, R. E., Faerman, S.R., Thompson, M.P. and McGrath, M. (2003). Becoming a master manager: A competency framework ( $3^{\text {rd }}$ ed.). New York: John Wiley and Sons, Inc.

Riccucci, N. M. and K. C. Naff (2008). Personnel management in government: Politics and process $\left(6^{\text {th }}\right.$ ed.). Boca Raton, FL: CRC Press.

Rush, C., and Kellough, E. (2011, June). Human resource professionalism in Georgia counties: Examining the extent and determinants of public managers' understanding of EEO law. Paper presented at the Public Management Research Conference, Syracuse, NY.

Selden, S. C. (2009). Human capital: Tools and strategies for the public sector. Washington, DC: CQ Press.

Selden, S.C., and Jacobson, W. (2007). Chapter four: Government's largest investment: Human resource management in states, counties, and cities. In P.W. Ingraham, In pursuit of performance: Management systems in state and local government (pp. 82-116). Baltimore, MD: John Hopkins University Press.

Selden, S.C. and Jacobson, W. (2003). Chapter five: Human resource management. In Paths to performance in state and local government: A final assessment from the Maxwell School of Citizenship and Public Affairs (pp. 101-132). Syracuse, NY: Campbell Public Affairs Institute, The Maxwell School of Syracuse University.

Streib, G., Benton, J. E., Byers, J., Cigler, B. A., Klase, K. A., Menzel, D. C., et al. (2007). Conducting research on counties in the 21st century: A new agenda and database considerations. Public Administration Review, 67, 968-983.

Svara, James H. (1996). Leadership and professionalism in county government. In D.C. Menzel, The American county: Frontiers of knowledge (pp. 109-27). Tuscaloosa, AL: University of Alabama Press.

Tompkins, J. (2002). Strategic human resource management in government: Unresolved issues. Public Personnel Management, 31, 95-110. 
Ulrich, D., Brockbank, W., Johnson, D., Sandholtz, K., and Younger, J. (2008). HR competencies: Mastery at the intersection of People and Business. Alexandria, VA: Society for Human Resource Management.

U.S. Office of Personnel Management. (1999). Looking to the future: Human resources competencies. Washington, DC: Author.

Van Riper, P. P. (1958). History of the United States civil service. Evanston, IL: Row, Peterson.

Yin, R. K. (1994). Case Study Research: Design and Methods (2 $2^{\text {nd }}$ ed.). Thousand Oaks, CA: Sage Publications. 